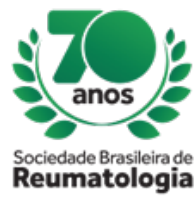

\title{
USE OF HYDROTHERAPY IN OSTEARTICULAR AFFECTIONS ON ELDERLY: A SYSTEMATIC REVIEW
}

Thaynara Sarmento Oliveira Almeida (Centro Universitário de João Pessoa, João Pessoa, PB, Brasil), Salomão Nathan Leite Ramalho (Faculdade de Medicina do Juazeiro do Norte, Juazeiro do Norte, CE, Brasil), Thassiany Sarmento Oliveira Almeida (Universidade Federal de Pernambuco, Campina Grande, PB, Brasil), Bianka Martins da Silva Nascimento (Centro Universitário de João Pessoa, João Pessoa, PB, Brasil), Francisco Victor Andrade Cavalcante (Centro Universitário de João Pessoa, João Pessoa, PB, Brasil), Mikhael Ranier Leite Ramalho (Faculdade de Medicina do Juazeiro do Norte, Juazeiro do Norte, $\mathrm{CE}$, Brasil), Raphael Henrique Lima Freire (Centro Universitário de João Pessoa, João Pessoa, PB, Brasil), Pablo Duarte de Lima (Centro Universitário de João Pessoa, João Pessoa, PB, Brasil)

\section{BACKGROUND}

: Among rheumatologic conditions, chronic low back pain, fibromyalgia and osteoarthritis are reported as the most common types of musculoskeletal disorders associated with significant functional limitations. This fact demonstrates the need for the insertion of therapies that help to improve the quality of life of patients, who are mostly elderly. Therefore, considering the musculoskeletal conditions due to aging, the benefits of aquatic exercise should be evaluated in elderly patients diagnosed with such diseases.

\section{MATERIALS AND METHODS}

selection and use of fudamentation references occurred from a systematized search in the following databases: MEDLINE-NLM, MEDLINE-EBSCO, Elsevier's Scopus, SciELO and the Cochrane Library. Randomized and quasi-randomized clinical trials evaluating the effects of aquatic exercises in older adults with musculoskeletal conditions were investigated in comparison with no exercise or land exercise using the descriptors extracted from DeCS between 2008 and 2018. The outcomes of interest will be pain, physical function and quality of life. The selected articles were submitted to quality scale The Physiotherapy Evidence Database (PEDro) score.

\section{RESULTS}

: Of the 12 included studies 11 were randomized controlled trials. During the study period, $50.0 \%$ of the studies were published in 2008. The most common musculoskeletal disorders were rheumatoid arthritis, fibromyalgia, low back pain and osteoporosis. The majority of studies reported improvements in pain after the hydrotherapy (92.3\%) and physical function (92.3\%). Physical function and quality of life resulted in positive scores, whereas pain presented negative score (reduction of pain). Participants were predominantly elderly, and eight $(61.5 \%)$ studies included participants with a mean age $>60$ years. This evaluation evidences that aquatic exercise offers moderate benefits for the elderly with musculoskeletal conditions, including reduction of pain, improvement of physical function and quality of life. Studies often confirm a marked sense of well-being in patients with osteoarthritis, and osteoporosis, however, the effects on quality of life in fibromyalgia and low back pain remains uncertain. In addition, there was considerable variability among the aquatic exercise programs used in each study.

\section{CONCLUSION}

At this point, the evidence suggests that aquatic exercise has beneficial effects on pain, physical function and quality of life in the elderly with musculoskeletal diseases. These benefits appear to be comparable between conditions and those obtained with ground exercise. However, further research are needed to understand the characteristics of hydrotherapy programs that provide the greatest benefit to the elderly. 